\title{
OS MEGAEVENTOS ESPORTIVOS NA AGENDA DAS POLÍTICAS PARA A EDUCAÇÃO FÍSICA ESCOLAR NO ESTADO DO RIO DE JANEIRO ${ }^{1}$
}

\author{
Alvaro Rego Millen Neto \\ Universidade Federal do Vale do São Francisco, Petrolina, Pernambuco, Brasil \\ Bruno Otávio de Lacerda Abrahão \\ Universidade Federal do Vale do São Francisco, Petrolina, Pernambuco, Brasil \\ Diego Luz Moura \\ Universidade Federal do Vale do São Francisco, Petrolina, Pernambuco, Brasil
}

\begin{abstract}
Resumo
$\mathrm{O}$ artigo tematiza os megaeventos esportivos sediados no Brasil durante as duas primeiras décadas do século XXI e discute a problemática da espetacularização. Tem como objetivo analisar os discursos da Secretaria de Estado de Esporte e Lazer do Rio de Janeiro (SEEL-RJ) que tangenciam esses megaeventos e verificar possíveis implicações para a dinâmica curricular da Educação Física na Secretaria de Estado de Educação do Rio de Janeiro (SEEDUC-RJ). As fontes utilizadas na pesquisa são publicações eletrônicas disponibilizadas no site da SEEL. Os dados indicam que os discursos da SEEL têm destacado o que seria uma demanda extraordinária para a Educação Física na SEEDUC. Essa demanda teria como objetivo a potencialização de projetos que apontam para a formação de uma elite esportiva no estado.
\end{abstract}

Palavras-chave: Megaeventos. Esporte. Espetáculo. Educação Física.

\section{Introdução}

O Brasil tem se destacado, neste início do século XXI, como anfitrião, na organização dos chamados megaeventos esportivos. A $20^{a}$ edição da Copa do Mundo da Federação Internacional de Futebol (FIFA) foi realizada no Brasil, em 2014, e a 31 a edição dos Jogos Olímpicos da era moderna tem como sede a cidade do Rio de Janeiro. Trata-se dos dois maiores eventos esportivos do planeta. Além deles, com menor proporção, destacaram-se a $15^{\mathrm{a}}$ edição dos Jogos Pan-Americanos (2007), a $5^{\mathrm{a}}$ edição dos Jogos Mundiais Militares (2011) e a $7^{\mathrm{a}}$ edição da Copa das Confederações da FIFA (2013) - os dois primeiros também foram realizados na cidade do Rio de Janeiro. Associando a intervenção governamental e a utilização de recursos públicos aos investimentos e interesses privados (MASCARENHAS, 2012) e dispondo do aparato midiático em sua máxima potência, os megaeventos esportivos se estabeleceram como uma das grandes estrelas da "sociedade do espetáculo" (DEBORD, 1997)2. Esses

\footnotetext{
${ }^{1} \mathrm{O}$ presente trabalho não contou com apoio financeiro de nenhuma natureza para sua realização.

${ }^{2}$ Guy Debord concebeu a metáfora "sociedade do espetáculo" para caracterizar a sociedade capitalista tardia. Em sua concepção, o espetáculo é um poderoso meio de controle ideológico dos modos de criação de sentido; uma forma teatral de distração que encobre, camufla e legitima os poderes políticos e
} 
eventos mobilizam as atenções de todo o planeta e, por imprimir periodicidade aos seus rituais, o controle e a mobilização que estão ao seu entorno não são comparáveis a nenhum outro fenômeno social. Sediá-los em solo brasileiro é uma empreitada que simboliza, numa perspectiva modernizadora e civilizatória, a grandiosidade e a potência de uma nação emergente, politicamente estável, economicamente viável e empreendedora. É sob essa bandeira, espetacularmente exagerada e distorcida, que a organização dos megaeventos esportivos se tornou uma das prioridades políticas do Brasil na segunda década deste século.

Essa representação, que foi e tem sido ideologicamente processada pelos governos brasileiros, não estabelece uma exceção na forma de promoção dos megaeventos. Desde o panen et circenses romano, passando pelos comícios nazistas de Nuremberg, que os grandes eventos espetaculares têm servido a interesses governamentais. Críticas específicas sobre ações de governo ligadas à promoção de megaeventos esportivos não são raras. Nesse sentido, Broudehoux (2011) mostrou como o sentimento de patriotismo acionado pela propaganda governamental, direcionada para os Jogos Olímpicos de Pequim em 2008, contribuiu para autopromover o governo e favorecer interesses de relações público-privadas que, de modo peculiar, se estabeleceram na China. Chatziefstathiou (2012), por sua vez, relacionou as ações governamentais britânicas que giraram em torno dos Jogos Olímpicos de Londres em 2012 com a afirmação de políticas para uma noção de cidadania neoliberal.

No Brasil, também há uma produção que aponta para essa problemática. Segundo Mascarenhas (2009), por exemplo, na "virada" dos anos 1980, a FIFA e o Comitê Olímpico Internacional (COI) se organizaram adotando novos princípios gerenciais e inseriram de vez o esporte no capitalismo global, tornando-se duas das maiores multinacionais do mundo. Desde então, passaram a atrair poderosos patrocinadores, a vender os direitos de transmissão de seus eventos e a realizar significativas parcerias com o poder público. Nessa mesma direção, Bracht e Almeida (2013) criticaram a orientação mercadológica que factualmente direciona a condução dos megaeventos esportivos e apontaram para a "parceria entre o poder público e a organização esportiva, que opera como um grande lobby econômico internacional do esporte, que usa (e abusa) do poder (e do dinheiro) público” (p.139).

Em outra ocasião, os mesmos autores (BRACHT; ALMEIDA, 2003) problematizaram as reações governamentais e os discursos que afloraram a partir da participação dos atletas brasileiros nos Jogos Olímpicos de Sydney, ocorridos no ano 2000. Como essa participação foi considerada fraca - o Brasil não obteve medalhas de ouro e ficou na $52^{\mathrm{a}}$ posição entre os países participantes -, o governo federal, em resposta ao clamor da população, criou o Programa Esporte na Escola e incluiu a palavra "obrigatório" no texto da Lei de Diretrizes e Bases da Educação Nacional $(\mathrm{LDB})^{3}$ que trata da Educação Física na Educação Básica. Ao investir no esporte escolar, essas reações governamentais teriam representado, de fato, "os interesses do sistema esportivo e os interesses corporativos da Educação Física" (p.92).

Essa ideia de que o país precisa ter uma elite esportiva que o represente internacionalmente de forma eficaz, especialmente nos megaeventos, não é nova e aparece naturalizada em parte da opinião pública e também do próprio campo profissional da Educação Física. Bracht (1992) há muito aponta para o fato de que a legitimidade da Educação Física tem sido garantida, em boa medida, pela sua função social de ensinar o esporte. Nesse prisma, caberia à Educação Física escolar participar do projeto de formação dessa elite esportiva, assumindo a função de compor uma base esportiva nacional, cuja meta central seria fornecer material humano apto a alcançar altos rendimentos esportivos.

econômicos.

${ }^{3}$ No que se refere à Educação Física, o texto original da LDB foi modificado em duas ocasiões. Na primeira delas, com a Lei 10.793, de 12 de dezembro de 2001, foi acrescentada a palavra obrigatório. 
Essa relação do esporte com a escola passou em revista e foi duramente criticada pela sociologia crítica do esporte (BRACHT, 1992) e pela pedagogia crítica da Educação Física no Brasil (CAPARROZ, 2007; STIGGER; LOVISOLO, 2009; MOURA, 2012). Essas críticas destacam uma categoria especial das manifestações esportivas, o esporte de rendimento. Fazem parte dela os atletas de elite, todo o aparato da mídia esportiva, os grandes clubes, associações, federações, comitês e suas competições. Uma das críticas que mais repercutiu academicamente no campo da Educação Física brasileira foi a ideia de que o esporte de rendimento tem códigos e valores - rendimento máximo, competição exacerbada, comparações objetivas, especialização, sobrepujança do outro, regras inflexíveis, etc. - que não são apropriados para a educação escolar (KUNZ, 1994).

Diante das problemáticas expostas, são objetivos deste artigo: a) analisar os discursos da Secretaria de Estado de Esporte e Lazer do Rio de Janeiro (SEEL-RJ) que tangenciam os megaeventos esportivos; b) verificar e problematizar possíveis implicações para a dinâmica curricular da Educação Física na Secretaria de Estado de Educação do Rio de Janeiro (SEEDUC-RJ).

\section{Metodologia}

Para dar conta de realizar uma das possíveis análises da inserção da temática referente aos megaeventos esportivos na dinâmica curricular da Educação Física na SEEDUC, optamos por centrar o foco investigativo no contexto das políticas públicas que têm influenciado o cotidiano escolar dessa rede de ensino. Para tal, procuramos descrever alguns dos investimentos pedagógicos realizados nas escolas da SEEDUC no que tange à problemática e compreender discursivamente os lugares da Educação Física e do esporte olímpico na dinâmica das políticas curriculares da SEEDUC.

Os documentos que constituíram as fontes para essa empreitada foram as publicações eletrônicas disponibilizadas no site da SEEL-RJ ${ }^{4}$. Consideramos essas publicações pertinentes para dar conta de nosso objetivo na medida em que elas estão próximas do que poderíamos considerar uma representação do discurso da SEEL. Trata-se de notícias produzidas por uma imprensa de Estado, cujos vínculos, interesses e representatividades estão, em alguma medida, postos. Os discursos que analisamos estão, portanto, perto de algo que poderíamos chamar de oficiais - dentro, é claro, do jogo de convicções, forças e poderes desse órgão público.

Foram catalogadas 38 notícias do site da SEEL, publicadas entre 18 de junho de 2011 e 23 de janeiro de 2013 - todas aquelas que, em algum grau, se referiam à Educação Física escolar. Esses dados foram analisados através de análise de conteúdo (BARDIN, 2011).

\section{Resultados e discussão}

As temáticas das publicações investigadas se restringem praticamente às competições esportivas escolares, especialmente as Olimpíadas Escolares. Das 38 matérias, 34 tratam especificamente desse evento, especialmente dos resultados e das conquistas das escolas e dos alunos que se destacaram. Dos quatro informes que não se referem diretamente às Olimpíadas Escolares, dois descrevem um projeto de treinamento de esportes olímpicos que tem como meta a formação de atletas em modalidades com pouca tradição no Brasil, um trata das co-

\footnotetext{
${ }^{4}$ Para este estudo, incluímos as notícias publicadas no site da SEEL, e não as da SEEDUC, pois, no estado do Rio de Janeiro, as políticas públicas que visam utilizar os tempos e espaços de aprendizagem das escolas da SEEDUC para pensar e agir na direção de uma formação esportiva que vise aos megaeventos esportivos também partem da SEEL. Entendemos que há uma interlocução, mesmo que nem sempre coesa e coerente, entre essas duas secretarias de Estado para dar conta dessa mesma missão.
} 
memorações relativas ao dia olímpico e um último se refere a outra competição esportiva, o Intercolegial.

O projeto de treinamento de esportes olímpicos teve seu primeiro polo implantado em uma escola modelo recentemente inaugurada (RIO DE JANEIRO, 2012n) no bairro da Tijuca, o C.E. Chico Anysio. Esse projeto educacional é uma parceria público-privada da SEEDUC e da SEEL com o Instituto Brasileiro de Mercado de Capitais (IBMEC). As modalidades olímpicas contempladas no projeto são a esgrima e a luta olímpica. De acordo com o depoimento da secretária de esporte e lazer, Márcia Lins ${ }^{5}$, presente na supracitada matéria, a escolha dessas modalidades teve como prerrogativa o fato de que há "bastante medalha olímpica em disputa: são 72 na luta e 30 na esgrima. Mas o principal de tudo é que são esportes de combate e de cidadania, porque os praticantes desenvolvem disciplina, autocontrole e equilíbrio emocional".

Há uma conotação positiva, no discurso da secretária, no que se refere à relação entre a prática esportiva, especificamente a das modalidades escolhidas, e o projeto de escolarização. Apesar de se tratar de um discurso ponderado, sem apresentar relações de causa e efeito, os projetos esportivos são valorizados por sua utilidade na escola para além da formação esportiva em si. Somando-se ao fato de que essas modalidades olímpicas não têm muita tradição no Brasil, o seu desenvolvimento acrescenta visibilidade e aceitação pública à proposta da escola modelo.

Outro instantâneo, no qual podemos perceber o viés discursivo da SEEL com relação à temática investigada por este artigo, refere-se à competição Intercolegial. Trata-se de um evento esportivo promovido pelo jornal $O$ Globo no qual participam, desde 1983, alunos de escolas públicas e privadas do estado do Rio de Janeiro. Em 2012, ano de sua $30^{\text {a }}$ edição, ele teve 265 escolas inscritas e organizou competições de 18 modalidades esportivas, divididas por categorias de acordo com a faixa etária, o sexo e o registro (ou não) em federações esportivas. O hóquei de grama, também um esporte olímpico com pouca tradição no Brasil, foi incluído nessa $30^{\mathrm{a}}$ edição.

A secretária Márcia Lins participou da cerimônia de abertura, em maio de 2012, e a SEEL emitiu uma notícia (RIO DE JANEIRO, 2012a) curiosa sobre o impacto social do Intercolegial no Rio de Janeiro. De acordo com a SEEL, o evento em tela "promove inclusão social e aquece o mercado dos professores de Educação Física", assim como "[...] muitos alunos da rede pública que se destacam na competição conseguem bolsas de estudos e acesso ao ensino de melhor qualidade". Em se tratando de uma nota pública emitida por uma secretaria de governo, essa afirmação é de uma sinceridade despudorada. Infelizmente, não há o que discordar. De fato, a qualidade das escolas públicas de nível básico no Brasil vai mal ${ }^{6}$. Mas o exagero da franqueza presente na matéria da SEEL não é o ponto que mais nos interessa.

\footnotetext{
${ }^{5}$ Márcia Beatriz Lins Izidoro é formada em jornalismo, profissão que exerceu nos anos 1980. Na década seguinte, ela ingressou na carreira política e exerceu funções administrativas na Secretaria Municipal de Fazenda e na Câmara dos Vereadores, no Rio de Janeiro, e na Câmara dos Deputados em Brasília. Posteriormente, foi subsecretária de Comunicação Social da Prefeitura do Rio de Janeiro e, a partir de 2007, ingressou, como subsecretária executiva, na então Secretaria de Estado de Turismo, Esporte e Lazer do Rio de Janeiro, cujo secretário era o atual prefeito do Rio de Janeiro, Eduardo Paes. Com a saída de Paes, em 2008, para participar das eleições municipais, Márcia Lins assume a secretaria e mantém-se no cargo até 2013. O atual secretário é Marco Antônio Cabral, filho do ex-governador Sérgio Cabral, que tomou posse assim que seu pai deixou o governo.

${ }^{6}$ Como exemplo, podemos citar a avaliação dos estudantes brasileiros - em sua maior parte inseridos nas redes públicas de educação - no Programme for International Studant Assessment (PISA). Em seu último relatório, disponibilizado em 2012 , o Brasil está ranqueado na $58^{\mathrm{a}}$ posição para matemática, na $55^{\mathrm{a}}$ para leitura e na $59^{\mathrm{a}}$ para ciências, dentre os 65 países que participaram da avaliação.
} 
Como demonstraram Millen Neto, Ferreira e Soares (2011), o mercado dos jogos estudantis, com suas representações sobre a qualidade das escolas e dos professores de Educação Física, é aquecido por eventos como o Intercolegial. Esse mercado gera investimentos maiores na formação esportiva dos alunos, como pode ser visto no caso da escola da rede municipal do Rio de Janeiro investigada por esses autores. Por outro lado, esses investimentos seguem as regras do mercado. Se a moeda de troca é o rendimento esportivo, o desenvolvimento do esporte escolar será, naturalmente, balizado por esse valor. No caso do Intercolegial, o Colégio Santa Mônica parece ser um investidor importante. Esse colégio oferece bolsas para seus alunos atletas e foi campeão geral do torneio de 2001 a 2013 de forma ininterrupta.

O outro evento esportivo noticiado pela SEEL, as Olimpíadas Escolares (também chamado de Jogos Escolares da Juventude), concentrou o foco da grande maioria das matérias sobre o esporte escolar publicadas no portal. A estrutura dessas competições é ampla e envolve uma pirâmide organizacional que vai desde as etapas estaduais, passando pelos jogos nacionais, e atingindo a culminância em competições de abrangência mundial.

Segundo as informações publicadas pela SEEL, na etapa estadual de 2012 (RIO DE JANEIRO, 2012b) participaram mais de 20 mil alunos, de 473 escolas fluminenses - incluindo-se as duas categorias etárias (A: de 12 a 14 anos; B: de 15 a 17 anos). As Olimpíadas Escolares nacionais da categoria A (RIO DE JANEIRO, 2012d; RIO DE JANEIRO, 2012e) ocorreram em setembro de 2012, em Poços de Caldas (MG), e suas disputas envolveram mais de quatro mil alunos. Dos 20 mil que disputaram os jogos estaduais no Rio de Janeiro, foram selecionados 157 atletas para representar o estado na etapa nacional da categoria A. Na categoria B (RIO DE JANEIRO, 2012m), as competições nacionais foram realizadas em Cuiabá (MT) e também contaram com a participação de cerca de quatro mil alunos, dos quais 191 representaram o estado do Rio de Janeiro. Informes sobre as conquistas dos atletas fluminenses foram fartamente noticiados, tanto nos jogos de Poços de Caldas como nos de Cuiabá. O portal da SEEL hospedou dez matérias com essa temática, publicadas entre 11 de setembro e 20 de dezembro de 2013.

A cidade australiana de Sydney sediou, entre 16 e 20 janeiro de 2013, o que seria uma etapa mundial das Olimpíadas Escolares, o Australian Youth Olympic Festival (AYOF) ${ }^{7}$. Para esse evento, a delegação brasileira foi constituída por 52 atletas, todos da categoria B, selecionados pelo Comitê Olímpico Brasileiro (COB) durante as etapas nacionais. Sete jovens fluminenses fizeram parte dessa delegação. O portal da SEEL divulgou uma matéria (RIO DE JANEIRO, 2013a), na semana anterior ao evento, que trouxe informações sobre os atletas fluminenses que foram para Sydney, dentre os quais se sobressaíram o corredor Júlio Cesar Nascimento e o nadador Matheus Santana. Os nadadores Leonardo Santos, Nathalia Almeida, Letícia Odorici e Luiz Altamir, além do arremessador Renan Cazuza, completaram a lista de atletas fluminenses que fizeram parte da delegação brasileira.

A aposta era grande sobre a participação de alguns deles. A matéria ressaltou que Matheus conseguiu bater o recorde nacional juvenil dos 50 metros livres que até então pertencia a César Cielo, campeão olímpico e atualmente detentor dos recordes mundiais dos 50 e dos 100 metros livres e do 4x50 medley. Matheus relata que abriu mão de muita coisa para investir na natação. Uma fotografia do outro atleta destacado, o corredor Júlio César, ilustrou a capa da matéria. Foi ressaltado que ele "já foi um aluno problemático por causa de notas baixas e, atualmente, é uma das promessas do atletismo". Não foram publicadas informações sobre o seu rendimento escolar após ter se tornado um potencial atleta olímpico, mas o informe (RIO DE JANEIRO, 2013b) que trouxe notícias de Sydney após o evento também usou a imagem de Júlio César como capa. O atleta carioca conquistou três medalhas no Festival Olímpico da

\footnotetext{
${ }^{7}$ Em 2013, foi realizada a sexta edição do AYOF, que contou com a participação de 1.700 atletas de 30 países.
} 
Juventude na Austrália. Foi destacado que "o segredo do sucesso de Júlio César é o treino". Também ficou claro que o investimento na formação esportiva desse jovem é grande e não tem a escola como base para o seu treinamento. Durante o ano de 2012, ele treinou de segunda a sexta entre as $8 \mathrm{~h} 30$ e as $11 \mathrm{~h} 30$, e em alguns sábados também, no Centro de Formação e Aperfeiçoamento de Praças da Polícia Militar. Fica claro que esses jovens estão realizando um investimento alto em suas formações esportivas, não sabemos até que ponto esse investimento contribui para a sua escolarização, ou com ela concorre.

Os alunos com deficiências também têm sua estrutura de competições esportivas escolares, dentro do que convencionou-se chamar de Olimpíadas Escolares ou, mais especificamente, Paralimpíadas Escolares. No Rio de Janeiro, ainda não há o desenvolvimento de uma etapa estadual das Paralimpíadas Escolares. Em 2012, as matérias da SEEL veicularam a existência de dois eventos que incluíram, em suas competições, provas para alunos com deficiências. Uma competição de atletismo (RIO DE JANEIRO, 2012g), no Estádio Célio de Barros, e uma de natação (RIO DE JANEIRO, 2012h), no Parque Aquático Júlio Delamare. Ambas faziam parte da programação da categoria B das Olimpíadas Escolares. O discurso presente nas notas aponta o caráter positivo desses eventos, exaltando a possibilidade de convivência entre atletas olímpicos e paralímpicos. Como a ideia de inclusão está em alta, a SEEL fez uso de um discurso que promovia essas suas ações de convivência entre deficientes e não deficientes como se elas significassem um marco, um "cenário sem precedentes", nas políticas de esporte escolar no Brasil.

Reparem que, se comparados com os alunos sem deficiências, os com deficiências tiveram pouquíssimo espaço nas agendas do esporte escolar no estado do Rio Janeiro. A estrutura grandiosa das Olimpíadas Escolares "incluiu" pessoas com deficiências em duas modalidades, em competições que se esgotaram em três dias, e foram realizadas dentro da própria estrutura montada para os alunos sem deficiências. Essa pequena participação ocorreu, não por acaso, em locais de maior visibilidade e foram prontamente noticiadas. Não consideramos que o que foi proposto para o esporte escolar para pessoas com deficiências seja um avanço, e tampouco caminhe para uma proposta de inclusão através do esporte. A palavra inclusão fortuitamente não foi utilizada no portal da SEEL, mas muitas vezes tem sido mal interpretada.

Millen Neto e Silva (2008) discutiram a origem do termo "inclusão" no campo acadêmico e da militância pelos direitos das pessoas com deficiências. Na forma com que foi pensada, a palavra "inclusão" é indissociável da ideia de respeito às diferenças. E, por oposição, não tem relação com a ideia de normalidade, da busca por um padrão de igualdade - definido a partir dos olhos e das características das pessoas sem deficiências. Incluir, portanto, não é tornar "igual" ou simplesmente compartilhar tempos e espaços. Incluir é oportunizar acesso, considerando as características e as necessidades das pessoas com deficiências. Uma sociedade inclusiva precisa levar em conta as diferenças e seus serviços públicos têm que se adequar a elas.

Apesar de não ter organizado uma competição interestadual significativa, o portal da SEEL destacou (RIO DE JANEIRO, 2012i) que o estado do Rio de Janeiro teve a segunda maior delegação - composta por 121 atletas - da etapa nacional das Paralimpíadas Escolares de 2012. A cidade de São Paulo sediou, entre os dias 17 e 19 de outubro, essa que foi a sétima edição do evento, no qual se reuniram 1.200 competidores de 24 estados e do Distrito Federal. Para se ter ideia da importância e da visibilidade política do evento (RIO DE JANEIRO, 2012j), em sua abertura estiveram presentes o governador de São Paulo, Geraldo Alckmin, e o então prefeito da capital, Gilberto Kassab. O estado do Rio de Janeiro foi o campeão dessa edição do torneio, e apenas duas notícias foram postadas no portal da SEEL sobre isso (RIO DE JANEIRO, 2012k; RIO DE JANEIRO, 2012l).

Em seu conjunto, as iniciativas públicas e privadas para o desenvolvimento do esporte escolar, para alunos com ou sem deficiências, parecem viver um momento de crescimento e 
de revisão no Brasil. O calendário nacional para esta década, que conta com o desenvolvimento dos maiores eventos esportivos mundiais, repercute em diferentes iniciativas e associações. A secretária Márcia Lins foi presidente do Fórum Nacional de Secretários Estaduais de Esporte, e a SEEL divulgou (RIO DE JANEIRO, 2012c) a sua participação em uma reunião, realizada em Palmas (TO) em maio de 2012, com a presença do então ministro do Esporte, Aldo Rebelo.

Nessa ocasião, o fórum dos secretários teria apresentado uma nova proposta de jogos estudantis para o ministro Rebelo. Essa proposta previa parcerias públicas entre as áreas de esporte, educação e saúde, de modo a permitir o desenvolvimento de questões transversais, como "o incentivo ao rendimento escolar, o combate ao uso de drogas e a redução do índice de obesidade na população". A inspiração para a proposta de parcerias do poder público veio dos Jogos Escolares Britânicos. O próprio ministro esteve em Londres para conhecer a proposta britânica e acompanhar uma delegação brasileira. Há, portanto, certo consenso com relação à importância desse alinhamento dos diferentes setores públicos que estão envolvidos com o esporte escolar e com as suas implicações sociais.

Em outro fórum que privilegiou a temática da gestão do esporte escolar, a secretária Márcia Lins afirmou que as referidas parcerias do poder público já impactaram positivamente na condução dos jogos estudantis. De acordo com o informe (RIO DE JANEIRO, 2012f) da SEEL, na etapa estadual das Olimpíadas Escolares de 2012 não houve registro de vitória por W.O., ou seja, a participação das escolas no evento foi absoluta. A secretária considerou que a "harmonia" entre as secretarias de esporte, educação e saúde foi o que possibilitou essa participação, pois "permitiu consolidar o evento no calendário das escolas". Faz-se necessário compreender o significado dessa ideia de "harmonia" entre as diferentes secretarias de governo. Parece-nos evidente que a construção dessa "harmonia" se pauta no desenvolvimento do esporte de alto rendimento visando ao espetáculo esportivo e desenvolvendo-o. A SEEL teria apoio, ou harmonia, de outras secretarias para isso. Nesse sentido, se essa fala da secretária reflete a realidade, as políticas de esporte escolar têm um potencial impacto na dinâmica curricular da Educação Física na SEEDUC.

\section{Considerações finais}

De um modo geral, os dados nos permitiram uma aproximação com a problemática dos megaeventos na medida em que explicitaram parte dos discursos de uma secretaria de Estado - a SEEL - que tem a tematização dos megaeventos nas escolas da SEEDUC como uma de suas pautas estratégicas - por razões expostas na introdução deste texto, essa tentativa de tematização tem sido mais enfática nos tempos atuais. Através das análises das notícias, pudemos verificar duas entradas que, em alguma medida, nos permitiram essa aproximação: por um lado, as parcerias público-privadas que visam a uma formação olímpica e, por outro, todo o aparato das competições esportivas escolares que também seguem a lógica do esporte do leque olímpico (KUNZ, 1994).

Com relação à parceria público-privada, presente no discurso da SEEL, ficou perceptível a potência, o apelo e a visibilidade de programas que levantam a bandeira do Brasil olímpico. O que está em jogo é a notória intenção de potencializar as chances de fortalecer a representatividade e o êxito da nação brasileira nos megaeventos esportivos - para o caso específico, nos Jogos Olímpicos. A opção por se investir no treinamento de modalidades esportivas nas quais o Brasil não tem tradição, e que dispõem de um volume maior de medalhas em disputa, deixa explícita a finalidade última do projeto - a obtenção de medalhas olímpicas. Para uma empresa privada, como o IBMEC, não há nada de incoerente. Essa empresa está investindo em um projeto educacional que tem uma aceitação social praticamente garantida. Há uma comoção social com o sentimento de empoderamento da identidade nacional prove- 
niente dos êxitos de atletas brasileiros nos megaeventos. É essa comoção social que garante a aceitação e a visibilidade dadas a um projeto como esse, independentemente dos resultados dos atletas em formação. Mesmo que não sejam formados bons atletas - no sentido do rendimento -, a empresa obterá os seus resultados, inclusive com boas chances de geração de mídia espontânea. O problema se intensifica quando uma secretaria de Estado pretende se valer de uma estratégia análoga à da empresa privada.

Essa estratégia de marketing é utilizada de modo semelhante no aparato que envolve as competições esportivas escolares. De um modo geral, a estrutura pensada e operada para esses jogos tem uma acentuada preocupação com o fim, com a obtenção de resultados que possam representar de forma exitosa as políticas de governo para o esporte escolar. Não é ao acaso que as notícias da SEEL se concentraram na divulgação desses êxitos.

O caso das competições (ou da ausência delas) para alunos com deficiências é emblemático para entendermos essa ênfase nos fins medidos em resultados (medalhas) que, em alguma medida, negligencia os meios, os contextos e as necessidades dos próprios alunos. Como apontamos na discussão dos resultados, a SEEL não realiza eventos esportivos específicos para alunos com deficiências. Eles são "incluídos" nas competições para os alunos sem deficiências. Ainda assim, a comitiva fluminense que representou o estado na etapa nacional das Paralimpíadas Escolares de 2012 venceu o torneio. Essa vitória foi capitalizada pelo discurso da SEEL.

Numa tentativa de síntese, poderíamos dizer que os megaeventos esportivos estão na pauta das discussões contemporâneas da sociedade brasileira. A partir daí, surge uma demanda para a Educação Física escolar no sentido de possibilitar condições de aprendizagem do seu conhecimento e de um posicionamento crítico e reflexivo sobre esses proeminentes fenômenos da sociedade contemporânea. A despeito disso, observamos que as preocupações de tematização dos megaeventos esportivos da SEEL do Rio de Janeiro não se ocupam de problematizar pedagogicamente as manifestações esportivas. Pelo que pudemos observar nas notícias analisadas, a demanda parece se concentrar na utilização do aparato escolar para viabilizar a obtenção de visibilidade para projetos que pretensamente apontem para a formação de uma elite esportiva no estado, com fins de justificar uma agenda de potencialização de resultados esportivos nos megaeventos. Trata-se de reproduzir a lógica e os códigos do esporte de rendimento na escola (BRACHT, 1992).

Por fim, acreditamos que a sociedade brasileira não tem absorvido e aceitado o discurso do espetáculo esportivo de modo totalmente passivo, alienado e submisso. Além de uma produção acadêmica crítica, o Brasil da segunda década do século XXI tem sido palco para uma movimentação social que há pelo menos 20 anos estava adormecida. As ações governamentais, em suas diferentes esferas, estão lidando com um crivo social mais intenso e crítico. Para lidar com esse contexto, parece haver certa moderação e cuidado com a emissão do discurso do espetáculo, pois a potência do espetáculo pode gerar um détournement (DEBORD, 1997) - desvios ou deflexões que voltam a pujança discursiva do espetáculo contra si. É justamente através desses desvios ou deflexões que os discursos alternativos, ou contradiscursos, têm a oportunidade de formar novas representações sobre os megaeventos esportivos e a Educação Física escolar no Brasil. Como diria Debord (1997), o espetáculo deve ser enfrentado por meios espetaculares. 


\title{
SPORT'S MEGA EVENTS IN THE POLICYAGENDAFORSCHOOL PHYSICAL EDUCATION IN RIO DE JANEIRO STATE
}

\begin{abstract}
The paper thematizes the sport's mega events held in Brazil during the first two decades of the twenty-first century and discusses the problematic of the spectacularization. It aims to analyze discourses of SEEL-RJ that tangent these mega events and identify possible implications for curricular dynamics of Physical Education in SEEDUC-RJ. The sources used in the research are electronic publications available on the SEEL's site. The data indicate that the discourses of SEEL have highlighted what would be an extraordinary demand for the Physical Education on SEEDUC. This demand would aim to expand projects related to the formation of elite sports in the state.
\end{abstract}

Keywords: Mega Events. Sports. Spectacle. Physical Education.

\section{LOS MEGA EVENTOS DEPORTIVOS EN LA AGENDA DE LAS POLÍTICAS PARA LA EDUCACIÓN FÍSICA ESCOLAR EN RIO DE JANEIRO}

\begin{abstract}
Resumen
El artículo tematiza los grandes eventos deportivos celebrados en Brasil durante las dos primeras décadas del siglo XXI y discute el problema de la espectacularización. Su objetivo es analizar los discursos de la Secretaría de Estado de Esporte e Lazer do Rio de Janeiro (SEELRJ) vinculadas a esos grandes eventos, así como verificar los posibles envolvimientos para la dinámica del currículo de la Educación Física en la Secretaría del Estado do Rio de Janeiro (SEEDUC-RJ). Las fuentes utilizadas en la investigación son publicaciones electrónicas disponibles en el sitio de la SEEL. Los datos indican que los discursos de la SEEL han destacado lo que sería una exigencia extraordinaria para la Educación Física en la SEEDUC. Esta exigencia tendría como objetivo el crecimiento de los proyectos que se direccionan a la estructuración de una élite deportiva en el estado.
\end{abstract}

Palabras clave: Mega Eventos; Deporte. Espectáculo. Educación Física.

\section{Referências}

BARDIN, L. Análise de conteúdo. São Paulo: Edições 70, 2011.

BRACHT, V. Educação Física e aprendizagem social. Porto Alegre: Magister, 1992.

Sociologia crítica do esporte: uma introdução. 2. ed. Ijuí, RS: Ed. Unijuí, 2003.

BRACHT, V.; ALMEIDA, F. Q. A política de esporte escolar no Brasil: a pseudovalorização da Educação Física. Revista Brasileira de Ciências do Esporte, Florianópolis, v. 24, n. 3, p. 87-101, maio 2003.

Esporte, escola e a tensão que os megaeventos esportivos trazem para a Educação Física Escolar. Em Aberto, Brasília, v. 26, n. 89, p. 131-143, jan./jun. 2013.

BROUDEHOUX, A. M. Imagem de poder: arquiteturas do espetáculo integrado na olimpíada de Pequim. Revista Novos Estudos, CEBRAP, São Paulo, v. 89, p. 39-56, mar. 2011. 
CAPARROZ, F. E. Entre a Educação Física na escola e a Educação Física da escola. 3. ed. Campinas, SP: Autores Associados, 2007.

CHATZIEFSTATHIOU, D. Active citizens and public policy: the example of London 2012 Olympic Games. International Journal of Sport Management Recreation \& Turism, Thrace, v. 9, p. 23-33, jun. 2012.

DARIDO, S. C.; RANGEL, I. C. A. Educação Física na escola: implicações para a prática pedagógica. Rio de Janeiro: Guanabara Koogan, 2005.

DEBORD, G. A sociedade do espetáculo. Rio de Janeiro: Contraponto Editora, 1997.

KUNZ, E. Transformação didático-pedagógica do esporte. Ijuí, RS: UNIJUÍ, 1994.

MASCARENHAS, F. Megaeventos esportivos e a Educação Física: alerta de tsunami. Movimento, Porto Alegre, v. 18, n. 1, p. 39-67, jan./mar. 2012.

MASCARENHAS, G. J. Globalização e espetáculo: o Brasil dos megaeventos esportivos. In: MELO, Victor A.; DEL PRIORE, Mary (Org.). História do esporte no Brasil: do Império aos dias atuais. São Paulo: Unesp, 2009. p.505-533.

MILLEN NETO, A. R.; SILVA, T. J. F. Inclusão educacional de alunos com síndrome de Down. Pensar a Prática, Goiânia, v. 11, n. 2, p. 105-113, maio/ago. 2008.

MILLEN NETO, A. R.; FERREIRA, A. C.; SOARES, A. J. G. Políticas de esporte escolar e a construção social do currículo de Educação Física. Motriz - Revista de Educação Física, Rio Claro, v. 17, n. 3, p. 416-423, jul./set., 2011.

MOURA, D. L. Cultura e Educação Física escolar: da teoria à prática. São Paulo: Phorte, 2012.

RIO DE JANEIRO (estado). Secretaria de Estado de Esporte e Lazer. Secretária de Esporte e Lazer participa da abertura do Intercolegial. Portal de notícias, Rio de Janeiro, 6 maio 2012a.

- Olimpíadas Escolares do Rio de Janeiro começam neste sábado (26/5) com festa no complexo esportivo da Rocinha. Portal de notícias, Rio de Janeiro, 24 maio 2012b.

. Ministro do esporte anuncia olimpíadas escolares ampliadas em fórum nacional de secretários estaduais de esporte. Portal de notícias, Rio de Janeiro, 25 maio 2012c.

Rio de Janeiro conquista 26 medalhas na etapa das olimpíadas escolares na categoria A, disputada em Poços de Caldas. Portal de notícias, Rio de Janeiro, 16 set.2012d.

Rio de Janeiro conquista 26 medalhas na etapa das Olimpíadas Escolares Nacional. Portal de notícias, Rio de Janeiro, publicada em 17 set. 2012e.

Etapa estadual de olimpíadas escolares vira case de sucesso de gestão esportiva. Portal de notícias, Rio de Janeiro, 19 set. 2012f. 
Olimpíadas Escolares no Rio de Janeiro promovem modelo inédito de disputa no atletismo. Portal de notícias, Rio de Janeiro, 27 set. 2012g.

Parque aquático Júlio Delamare reúne estudantes para competições olímpicas e paralímpicas de natação. Portal de notícias, Rio de Janeiro, 9 out. de 2012h.

. Rio de Janeiro participa da $7^{\mathrm{a}}$ edição das Paralimpíadas Escolares com a segunda maior delegação do país. Portal de notícias, Rio de Janeiro, 15 out. 2012i.

Delegação do Rio de Janeiro participa da cerimônia de abertura das Paralimpíadas Escolares em São Paulo. Portal de notícias, Rio de Janeiro, 17 out. 2012j.

O Rio de Janeiro é campeão nacional das Paralimpíadas Escolares 2012. Portal de notícias, Rio de Janeiro, 19 out. 2012k.

. Rio de Janeiro é campeão das Paralimpíadas Escolares. Portal de notícias, Rio de Janeiro, 21 nov. 20121.

Rio de Janeiro conquista as primeiras nas Olimpíadas Escolares 2012, em Cuiabá. Portal de notícias, Rio de Janeiro, 29 nov. 2012m. dez. 2012n.

Governador inaugura escola modelo na Tijuca. Portal de notícias, Rio de Janeiro, 18

. Sete atletas do Rio de Janeiro disputarão Festival Olímpico da Juventude na Austrália. Portal de notícias, Rio de Janeiro, 9 jan. 2013 a.

Carioca de 16 anos conquista três medalhas no Festival Olímpico da Juventude, Austrália. Portal de notícias, Rio de Janeiro, 22 jan. 2013b.

STIGGER, M. P.; LOVISOLO, H. (Org.). Esporte de rendimento e esporte na escola. Campinas, SP: Autores Associados, 2009.

Endereço para correspondência:

amillen@gmail.com

Alvaro Rego Millen Neto

Universidade Federal do Vale do São Francisco

Avenida José de Sá Maniçoba S/N

Centro

56304205 - Petrolina, PE - Brasil 